\title{
Jefferson
}

Thomas Jefferson University

$\overline{\text { HOME OF SIDNEY KIMMEL MEDICAL COLLEGE }}$

JHN Journal

Volume 14

Issue 1 Summer 2019

Article 1

Summer 2019

\section{Sacroiliac Joint Fusion - Impact of a New Image-Guidance Protocol on Safety and Complications}

\author{
Christian Hoelscher, MD \\ Thomas Jefferson University \\ Daniel Franco, MD \\ Thomas Jefferson University \\ Joshua Heller, MD, MBA \\ Thomas Jefferson University
}

Follow this and additional works at: https://jdc.jefferson.edu/jhnj

\section{Let us know how access to this document benefits you}

\section{Recommended Citation}

Hoelscher, MD, Christian; Franco, MD, Daniel; and Heller, MD, MBA, Joshua (2019) "Sacroiliac Joint Fusion

- Impact of a New Image-Guidance Protocol on Safety and Complications," JHN Journal: Vol. 14 : Iss. 1 , Article 1.

DOI: https://doi.org/10.29046/JHNJ.014.1.001

Available at: https://jdc.jefferson.edu/jhnj/vol14/iss1/1

This Article is brought to you for free and open access by the Jefferson Digital Commons. The Jefferson Digital Commons is a service of Thomas Jefferson University's Center for Teaching and Learning (CTL). The Commons is a showcase for Jefferson books and journals, peer-reviewed scholarly publications, unique historical collections from the University archives, and teaching tools. The Jefferson Digital Commons allows researchers and interested readers anywhere in the world to learn about and keep up to date with Jefferson scholarship. This article has been accepted for inclusion in JHN Journal by an authorized administrator of the Jefferson Digital Commons. For more information, please contact: JeffersonDigitalCommons@jefferson.edu. 


\section{Sacroiliac Joint Fusion - Impact of a New Image- Guidance Protocol on Safety and Complications}

\author{
Christian Hoelscher, MD; Daniel Franco, MD; Joshua Heller, MD, MBA \\ Department of Neurological Surgery, Thomas Jefferson University, Philadelphia, \\ Pennsylvania, 19107
}

\section{INTRODUCTION}

Low back pain is a common affliction impacting patients worldwide. The burden of low back pain on modern society in terms of direct costs associated with diagnosis and treatment, as well as indirect costs such as time missed from work for both patients and caregivers, is estimated to be as high as $\$ 100$ billion annually in the United States alone..$^{1,2}$ Up to $2-3 \%$ of physician visits are thought to be related to chronic low back pain. ${ }^{1,3}$ While the traditional focus of healthcare providers has been on lumbosacral pathology, sacroiliac joint dysfunction is an underappreciated and underdiagnosed cause of low back pain. Previous studies ${ }^{3-8}$ have suggested that $15-30 \%$ of chronic low back pain is due to pathology located in the sacroiliac joint. Historically, recognition of this pathology was difficult, limited by lack of standardized diagnostic criteria and disease-specific outcome measures. Traditional treatment focused on conservative therapy, such as physical therapy with focus on core and pelvic stability, orthoses, pain and anti-inflammatory medication, weight loss, intra- or peri-articular injec-

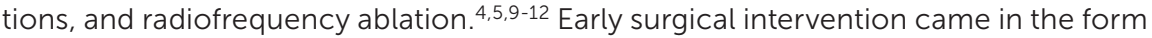
of morbid open approaches often utilizing iliac crest autografting. More recently, minimally invasive techniques for sacroiliac fusion have been developed that allow for significant sparing of muscle dissection, shorter operating room times and blood loss, reduced length of stay, and fewer complications. ${ }^{13-17}$ Such techniques are often performed with fluoroscopic guidance. However, three-dimensional sacral anatomy can be challenging to conceptualize on fluoroscopic imaging and several centers are now beginning to perform the procedure utilizing image-guidance with intraoperative CT data. This is particularly helpful in patients with transitional lumbosacral anatomy or those undergoing revision procedures. Complications such as pseudarthrosis and neural injuries, while rare, are often associated with need for revision surgery and poorer outcome. ${ }^{18,19}$ The transition to CT-based image-guidance aims to reduce such complications. The purpose of this study is to review our series of minimally invasive sacroiliac fusion with a focus on safety and complications, and to review differences in these parameters between patients undergoing fluoroscopic technique versus CT-based image-guidance.

\section{METHODS}

We performed a PubMed literature search utilizing the following terms: sacroiliac joint fusion, SI joint fusion, minimally invasive, complications, image guidance. Only English language articles were reviewed. All studies documenting large case series and prospective trials regarding minimally invasive sacroiliac joint fusion were included. The data extraction was performed by two reviewers ( $\mathrm{CH}, \mathrm{DF})$, and reviewed by the senior author $(\mathrm{JH})$. The selected studies were analyzed, and relevant results were reviewed. In addition, a retrospective review of minimally invasive sacroiliac joint fusion procedures performed at our institution was performed spanning 2013-present. Patient demographics, type of imaging used (traditional fluoroscopy versus CT and Stealth image guidance) follow-up, and complications were recorded. Complications of particular interest were neurologic complications, pseudarthrosis, and need for revision surgery, among others. Comparisons were made between patients undergoing fluoroscopy and CT/Stealth guidance.

\section{Technique - Fluoroscopy}

After administration of general endotracheal anesthesia and placement of neuromonitoring leads, the patient is positioned prone on a Jackson table with careful attention to adequately padding pressure points and ensuring the abdomen hangs free. Fluoroscopy is used to mark the skin on the ipsilateral side the location of the sacral ala as well as the posterior aspect of the sacral canal. This serves as a marking point for the incision and helps with orientation of the implants (Figures 1-2). The skin is then prepped and draped in standard fashion. The incision is created with a \#10 blade and the subcutaneous tissue is dissected with monopolar electrocautery. A hemostat is used to open the fascia. A Steinmann pin is placed at the level of the ilium with lateral fluoroscopic guidance at a location below the sacral ala. Pelvic inlet and outlet views are obtained to demonstrate adequate positioning of the pin relative to the ilium, SI joint, and neural foramina (Figure 3). The first pin is then tamped through the ilium, across the SI joint, and into the sacrum. The soft tissue dilator is then placed over the pin, followed by a soft tissue protector. A drill is then advanced over the pin and advanced across the SI joint. The broach is then advanced across the SI joint with fluoroscopic guidance on lateral, pelvic inlet, and pelvic outlet views. The broach is then removed. The first implant is then advanced over the pin and tamped into position using fluoroscopic guidance (Figure 4). A parallel pin guide is then used to assist with placement of the next Steinmann pin inferior to the first implant, and the procedure is repeated for a second implant. The parallel pin guide is then used to place a Steinmann pin in the ideal location of the third implant relative to the first two. The authors preference is to place the third implant it in a position anterior and inferior to the first. The same procedure is repeated for placement of the final 


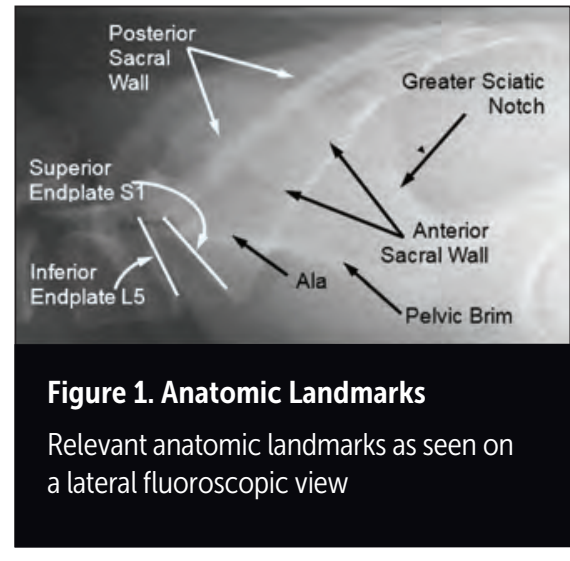

implant. Neuromonitoring signals are checked after placement of each implant. Final fluoroscopic images are obtained confirming trajectory and final position across the SI joint into the sacrum without breach of the neuroforamina. The wound is then copiously irrigated with antibiotic solution. The soft tissue is anesthetized with Marcaine solution. The deep dermal layer is closed with 2-0 vicryl suture in an inverted fashion and the skin is closed with a 4-0 monocryl subcuticular suture, followed by skin glue and a sterile dressing.

\section{Technique - CT/Stealth Image Guidance}

After administration of general endotracheal anesthesia and placement of neuromonitoring leads, the patient is positioned prone on a Jackson table with careful attention to adequately padding pressure points and ensuring the abdomen hangs free. The low back and lateral pelvic area on the side to be fused are prepped and draped according to standard protocol. A small incision is made over the contralateral posterior superior iliac spine (PSIS) with a \#10 blade, and the fascia opened sharply with monopolar electrocautery. The pin for the Stealth reference frame is advanced into the PSIS. The O-arm is then draped and brought into the surgical field. After confirmation of appropriate anteroposterior (AP) and lateral views centered over the SI joint to be fused, an intraoperative $\mathrm{CT}$ is obtained and transmitted to the Stealth work station. The $\mathrm{O}$-arm is then removed from the field. The passive planar probe is used to mark the location of the sacral ala on the skin, as well as
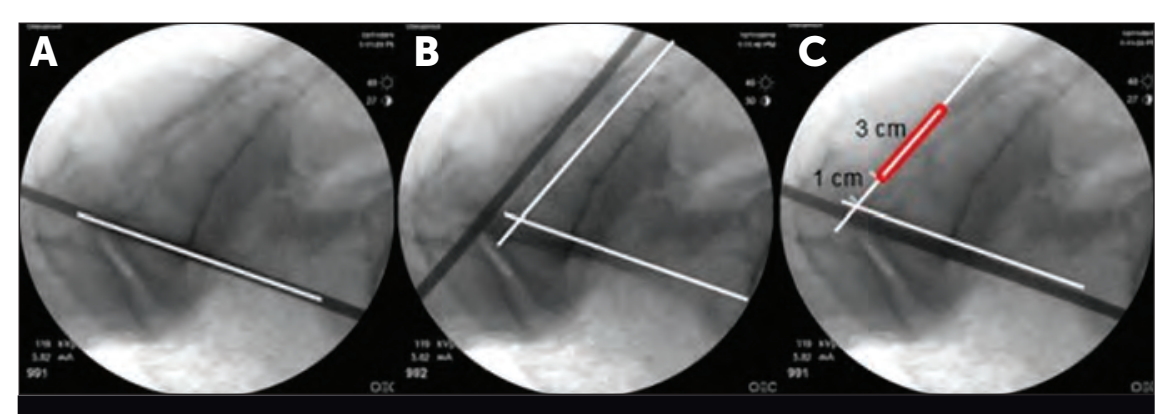

Figure 2. Incision Planning

Incision planning with pins placed along the sacral alae (A) and posterior sacral wall (B). The incision is then created about $3 \mathrm{~cm}$ in length along the posterior sacral wall, approximately $1 \mathrm{~cm}$ below the sacral alae (C).
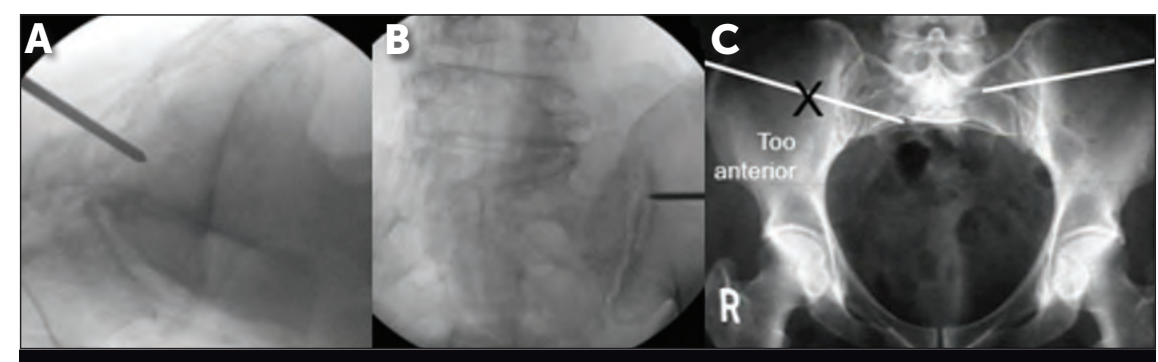

Figure 3. Pin Placement

Pin placement about $1 \mathrm{~cm}$ below the sacral ala (A). Pelvic outlet views are obtained to advance the pin parallel to the S1 endplate without breaching the sacral foramina (B). Pelvic inlet views are obtained to ensure that the pin placement is appropriate in the anterior-posterior plane (C).

the location of the posterior aspect of the sacral canal on the ipsilateral side. This serves as the incision and reference for graft placement. The skin is then incised with a \#10 blade, with dissection carried down through the subcutaneous tissue with monopolar electrocautery. The fascia is opened with a hemostat. The navigated universal drill guide is then placed to the level of the ilium (Figure 5). The first implant is planned and transferred to the work station (Figure 6). The drill guide is then used to place a guidewire through the ilium to the planned depth. A soft tissue dilator is then placed over the wire, followed by a soft tissue protector. The navigated drill is then used to drill over the guidewire across the ilium, the SI joint, and into the sacrum. The drill is removed, and a navigated broach is then advanced and tamped down the same trajectory. Neuromonitoring is then checked and confirmed to be unchanged from baseline. The soft tissue protector is then removed. A parallel pin guide with a navigated universal drill guide is then used to mark the location for the starting point of the second implant, inferior to the first graft. The process is repeated for the second and third grafts. Neuromonitoring is checked after placement of each graft. Once all grafts have been placed, a second intra-operative CT is obtained to confirm appropriate positioning. The wound is then copiously irrigated with antibiotic solution. The soft tissue is anesthetized with Marcaine solution. The deep dermal layer is closed with 2-0 vicryl suture in an inverted fashion and the skin is closed with a 4-0 monocryl subcuticular suture, followed by skin glue and a sterile dressing. A single monocryl suture is placed in the contralateral PSIS pin site. Figure 7 shows an example of post-operative imaging demonstrating hardware position. 


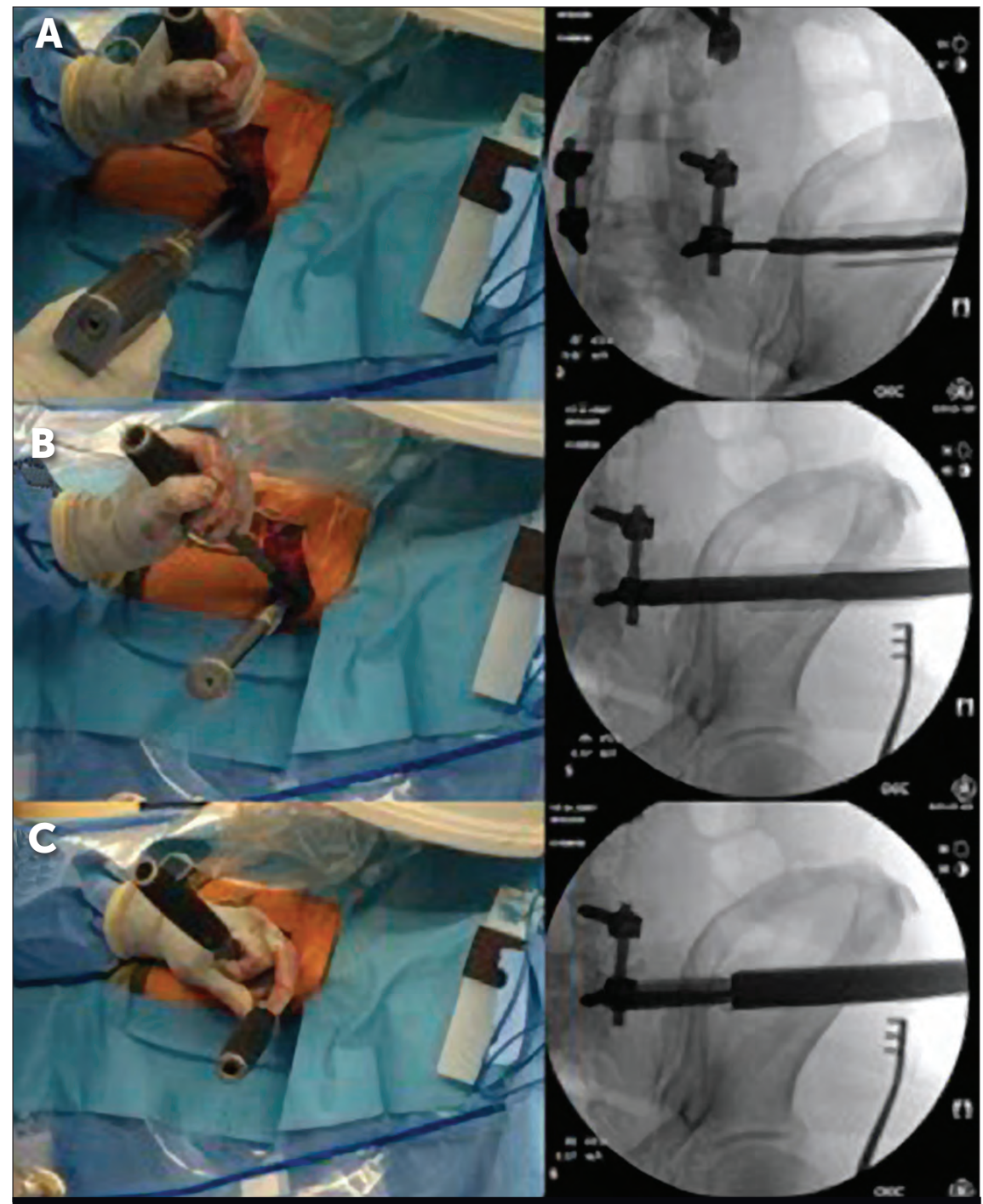

Figure 4. Implant Placement

On pelvic outlet views, the drill is advanced over the pin (A), followed by broach placement (B) followed by seating the final implant (C).

\section{RESULTS}

A total of 70 procedures were performed on 67 patients. Baseline characteristics and demographics are shown in Table 1. The average age was 50.4, with a male: female ratio of 49:21. BMI averaged 30.2. Co-morbidities of interest included 9 patients with diabetes, 13 with lumbosacral scoliosis, 5 with confirmed osteoporosis, 29 with a history of smoking, 5 active smokers, and 37 with prior lumbar surgery. Followup averaged 7.6 months. A total of 5 cases were revision procedures. Forty-six procedures were performed utilizing fluoroscopy, while 24 utilized CT with Stealth navigation. Complications for the entire cohort are demonstrated in Table 2. There was a total of 7 complications noted: 2 neurologic complications (both $\mathrm{S} 1$ radiculopathies), two cases of pseudarthrosis, 2 hematomas, and one washout that revealed only "thickened subfascial tissue". Overall 7 patients underwent revision surgery. Table 3 shows comparisons in terms of baseline demographic and co-morbidities between the fluoroscopy and CT groups, while Table 4 shows complications between the two groups. Baseline demographics were notable for a trend towards a higher proportion of females and a higher proportion of revision surgery in the CT cohort. Complications were overall fairly rare and did not reach statistical significance between groups. There were 5 total complications in the fluoroscopy group compared to two in the CT cohort. There were 4 combined cases of neurologic deficit and pseudarthrosis, all of which occurred in the fluoroscopy group. Revision procedures were required in 5 procedures utilizing fluoroscopic guidance, compared to one in the CT group.

\section{DISCUSSION}

Sacroiliac joint dysfunction is an increasingly-recognized source of low back pain. This patient population has historically been very difficult to treat, with an extremely high burden of cost on both a direct and indirect basis, often with frustrating outcomes and high rates of persistent disability. ${ }^{3-5}$ The traditional focus of back pain has been on diagnosis and managing lumbosacral pathology as well as neuropathic pain. Sacroiliac evaluation is only more recently gaining traction. Given that the SI joint is the largest articular surface in the human body, with fairly complex biomechanics central to force transmission across the complicated lumbosacral-pelvic anatomy, it is not surprising that this may be another source of pain.

Previous estimates of up to $30 \%$ of chronic back pain being referable to the SI joint have been published by numerous authors. ${ }^{3-7}$ Recognition of this pathology has been limited in the past by a lack of clear diagnostic criteria. With increasing focus on this clinical entity, there is starting to be more consensus on appropriate means of diagnosing SI joint dysfunction. Patient history will often reveal pain in the gluteal region, located in the region of the PSIS. This may or may not be associated with a radiating component down the lower extremity and/or into the hip and groin. Pain is often worse in the sitting position. Physical examination is typically notable for positive findings on the Fortin's Finger test, as well as 


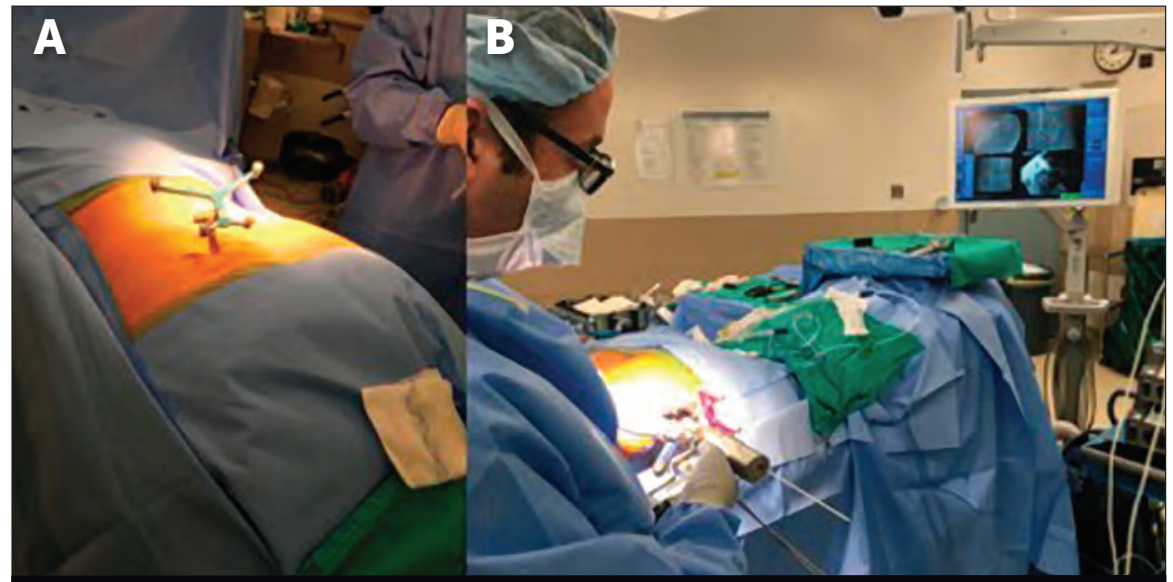

Figure 5. CT/Stealth Setup

A navigation pin is advanced into the contralateral PSIS and an intraoperative CT scan is obtained (A). The navigated drill guide can then be advanced to the level of the ilium after an appropriate incision has been made, and implant planning can proceed (B).

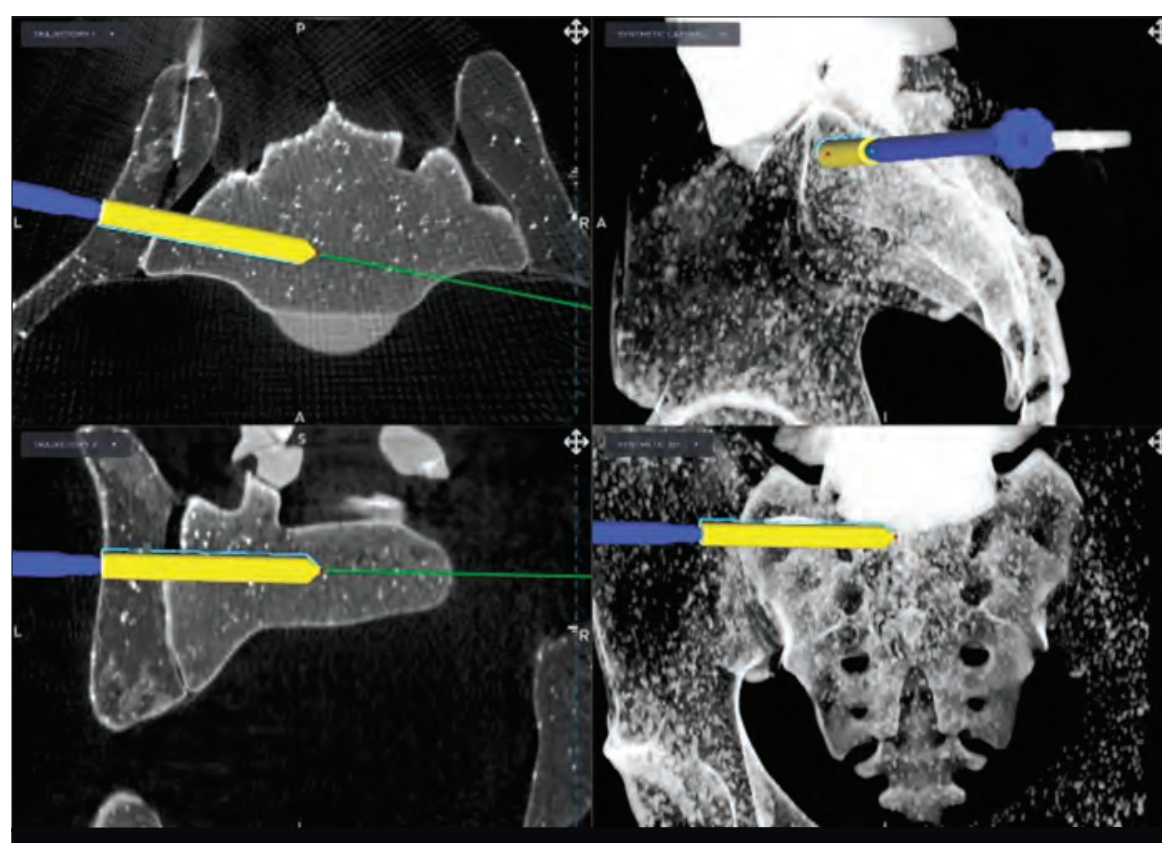

Figure 6. Implant Planning

Implant planning using the Stealth workstation)

reproduction of pain in at least three of five provocative SI joint testing maneuvers including pelvic distraction, thigh thrust, direct compression, flexion/abduction/ external rotation (FABER), and Gaenslen's maneuver. Intrarticular SI joint injections with local anesthetic are used to confirm the diagnosis. Diagnostic injections relieve patient pain by at least $50-60 \%$ prior to considering surgical fusion of the joint. Therapeutic injections with steroid can be used to try to provide longer lasting relief.

Evidence in favor of minimally invasive SI joint fusion has largely been limited to retrospective studies or smaller prospective cohort studies. ${ }^{8-11,14-17}$ Recently two large prospective, randomized controlled trials (RCT) have been published lending further support to the benefit of SI joint fusion in carefully selected patients. Polly et a ${ }^{20,21}$ performed an industry-sponsored trial of minimally invasive SI fusion compared to best medical management. A total of 148 patients were randomized (102 to SI fusion, 46 non-surgical). The primary endpoint was pain as measured by VAS, with secondary endpoints including disability on ODI, health-related quality of life on the EuroQol-5D (EQ5D) and Short Form 36 (SF 36). At 24-month follow-up, VAS improved from 82.3 to 26.7 in the surgical group, compared to 82.2 to 70.3 in the non-surgical group. Similar disparity was noted on ODI, EQ5D, and SF-36. At the 6-month time point crossover was allowed, and $39 / 44$ patients in the non-surgical group elected for surgery and enjoyed similar benefit as those originally randomized to surgery. Overall complication rates were not significantly different between groups. Dengler et $\mathrm{al}^{8}$ performed a prospective randomized trial, again industry sponsored, that randomized 103 patients to minimally invasive fusion $(n=52)$ or conservative therapy $(n=51)$. The primary endpoint was back pain on the VAS scale, with secondary endpoints including leg pain VAS, ODI, EQ-5D, and $\mathrm{SI}$ joint function via straight leg raise. At 12-month follow-up there was significant benefit of surgery compared to conservative management across all of these measures. Again, crossover was allowed at 6 months. Crossover rates were high, and benefits were similar to those originally randomized to surgery. The authors documented 6 procedurerelated complications, of which two required revision surgery.

The focus of this study was complication avoidance and safety. This has been explored by previous authors but to our knowledge no data is available comparing fluoroscopic versus CT -based techniques. Schoell et al ${ }^{18}$ performed the largest evaluation of safety for SI fusion, reporting complication rates in a minimally-invasive $\mathrm{SI}$ joint fusion patient population. They used CPT and ICD-9 codes to identify primary (non-revision) minimally invasive SI fusion procedures in a large nationwide insurance database. They 


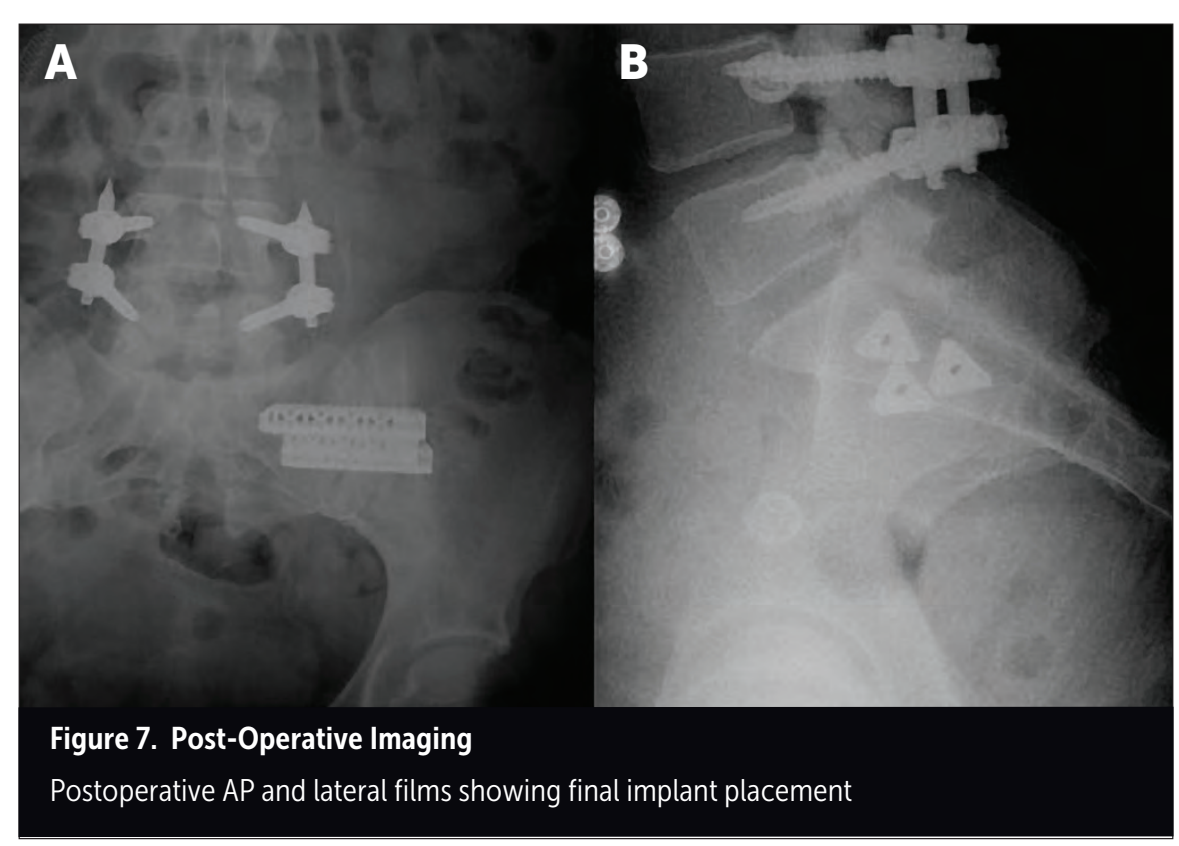

Table 1. Baseline Characteristics

\begin{tabular}{|l|c|}
\hline Age & 50.4 \\
\hline M:F & $49: 21: 00$ \\
\hline BMI & 30.2 \\
\hline Diabetes & 9 \\
\hline Scoliosis & 13 \\
\hline Osteoporosis & 5 \\
\hline Prior Smoker & 29 \\
\hline Current Smoker & 5 \\
\hline Revision & 5 \\
\hline Prior Lumbar Surgery & 37 \\
\hline Fluoro:Nav & $46: 24: 00$ \\
\hline Baseline demographics and co-morbidities for patients undergoing SI fusion. \\
\hline
\end{tabular}

Table 2. Complications for the Entire Cohort

\begin{tabular}{|l|c|}
\hline & Value \\
\hline Sacral radiculopathy & 2 \\
\hline Pseudoarthrosis & 2 \\
\hline Other & 3 \\
\hline Revision & 7 \\
\hline \multicolumn{2}{|l|}{ This table demonstrates complication profiles for the entire cohort. } \\
\hline
\end{tabular}

identified a total of 469 patients and noted an overall complication rate of $13.2 \%$ within 90 days, and $16.4 \%$ within 6 months. Notable complications at 90 days and 6 months respectively included new lumbar pathology (3.6\% and $5.3 \%$ ), infection $(3.6 \%$ and $4.1 \%)$ "nervous system" complications (4.3\% and 6.2\%), and chronic pain $(2.6 \%$ and $4.1 \%)$. These rates of complications are somewhat higher than compared to previously published RCT and prospective cohort studies, particularly in regard to infection with has often been quoted around 1\% for minimally invasive SI fusion. ${ }^{8-11,14-}$ 17,20,21 Review of our complication data confirms the safety of the procedure, with an overall complication rate of $10 \%$ at mean follow-up of 7.6 months. Of note, we had no cases of infection. There were 3 washouts performed (2 hematoma, one which noted only "thickened subfascial tissue"). Our transition to O-arm image guidance appears to have had a positive impact on the complication profile, although the overall low patient numbers and complication rate has prevented this difference from reaching statistical significance as yet. Of particular interest to this study was our rate of neurologic deficit and symptomatic pseudarthrosis; two cases of each occurred, both in the fluoroscopic group. While rare, when such complications occur, they almost invariably result in revision surgery with possible longterm implications for patient outcome. Proper implant placement is critical to avoiding such complications and should be improved with more precise image guidance. While fluoroscopy is a useful adjunct in this regard, the need for sophisticated understanding of sacro-pelvic anatomy on pelvic inlet, pelvic outlet, lateral, and other views can present a steep learning curve. Revision surgery and transitional anatomy can make the procedure more difficult, even in very experienced hands. Threedimensional image guidance such as CT with Stealth navigation is helpful in this regard, and the lack of implant misplacement in our cohort of 24 navigated cases, even with a significantly higher proportion of revision cases in this group, is a testament to that. An additional consideration in terms of complications and safety worth mentioning is successful fusion across the joint. Our study is limited in that we do not have routine post-operative References 
Table 3. Baseline Characteristics Between Groups

\begin{tabular}{|l|c|c|c|} 
& Fluoro $(n=46)$ & CT $(n=24)$ & P-Value \\
\hline Age & 50.6 & 49.9 & $*$ \\
\hline M:F & $17: 29$ & $4: 20$ & 0.078 \\
\hline BMI & 30.5 & 29.5 & $*$ \\
\hline Diabetes & 5 & 4 & $*$ \\
\hline Scoliosis & 9 & 4 & $*$ \\
\hline Osteoporosis & 4 & 1 & $*$ \\
\hline Prior Smoker & 18 & 11 & $*$ \\
\hline Current Smoker & 4 & 1 & $*$ \\
\hline Revision & 1 & 4 & $<0.05$ \\
\hline Prior Lumbar Surgery & 24 & 13 & $*$ \\
\hline
\end{tabular}

This table demonstrates baseline characteristics and comorbidities between the two groups. * denotes a $p$-value $>0.1$.

Table 4. Baseline Characteristics Between Groups

\begin{tabular}{|l|c|c|c|}
\hline & Fluoro $(n=46)$ & $C T(n=24)$ & P-Value \\
\hline Sacral radiculopathy & 2 & 0 & $*$ \\
\hline Pseudoarthrosis & 2 & 0 & $*$ \\
\hline Other & 1 & 2 & ${ }^{*}$ \\
\hline Revision & 5 & 2 & ${ }^{*}$ \\
\hline \multicolumn{4}{|l|}{ This table demonstrates complication profiles for both groups. ${ }^{*}$ denotes a p-value >0.1. } \\
\hline
\end{tabular}

CT scans to evaluate bony bridging across the SI joint. Previous studies have quoted fusion rates at 1-2 years postoperative in the range of $80-97 \% .15,17,19$ Two of our patients had documented symptomatic pseudarthrosis requiring revision, both in the fluoroscopy group. However, overall statements regarding solid fusion across the SI joint are difficult to generate with our data given the lack of protocolized follow-up CT imaging.

This study has limitations. Most notable is the retrospective nature of the analysis, and relatively low patient numbers. Furthermore, the duration of follow-up in this cohort is short, and longer-term follow-up would be helpful. Fusion across the SI joint was difficult to assess, and a standardized protocol for post-operative CT imaging to formally evaluate this would be helpful to get a better understanding of pseudarthrosis rates.

\section{REFERENCES}

1. Hoelscher C, Riley J, Wu C, Sharan A. CostEffectiveness Data Regarding Spinal Cord Stimulation for Low Back Pain. Spine. 2017 Jul 15:42 Suppl 14:S72-S79

2. Sharan A, Riley J, Hoelscher C. An Overview of Chronic Spinal Pain: Revisiting Diagnostic Categories and Exploring an Evolving Role for Neurostimulation. Spine. 2017 Jul 15;42 Suppl 14:S35-40.

3. Zaidi HA, Montoure AJ, Dickman CA. Surgical and Clinical Efficacy of Sacroiliac Joint Fusion: A Systematic Review of the Literature. J Neurosurg Spine. 2015 Jul;23(1):59-66.

4. Murakami E, Kurosawa D, Aizawa T. Treatment Strategy for Sacroiliac Joint-Related Pain at or Around the Posterior Superior Iliac Spine. Clin Neurol Neurosurg. 2018 Feb;165:43-46

5. Polly DW Jr. The Sacroiliac Joint. Neurosurg Clin N Am. 2017 Jul;2893):301-312.

6. Vanaclocha-Vanaclocha V, Herrera JM, SaizSapena N, Rivera-Paz M, Verdu-Lopez F. High Frequency of Lumbar fusion in Patients Denied Surgical Treatment of the Sacroiliac Joint. Br J Neurosurg. 2018 Nov 19:1-5.
7. Schmidt GL, Bhandutia AK, Altman DT Management of Sacroiliac Joint Pain. J Am Acad Orthop Surg. 2018 Sep 1;26(17):610-616

8. Dengler JD, Kools D, Pflugmacher R, Gasbarrini A, Prestamburgo D, Gaetani P, van Eeckhoven E, Cher D, Sturesson B. 1-Year Results of a Randomized Controlled Trial of Conservative Management vs. Minimally Invasive Surgical Treatment for Sacroiliac Joint Pain. Pain Physician. 2017 Sep;20(6):537-550.

9. Kibsgard TJ, Roise O, Sudmann E, Stuge B Pelvic Joint Fusions in Patients with Chronic Pelvic Girdle Pain: A 23-Year Follow-Up. Eur Spine J. 2013 Apr;22(4):871-7.

10. Rainov NG, Schneiderhan R, Heidecke V. Triangular Titanium Implants for Sacroiliac Joint Fusion. Eur Spine J. 2018 Dec 18.

11. Kube RA, Muir JM. Sacroiliac Joint Fusion: One Year Clinical and Radiographic Results Following Minimally Invasive Sacroiliac Joint Fusion Surgery. Open Orthop J. 2016 Nov 30;10:679-689.

12. Rappoport LH, Luna IY, Joshua G. Minimally Invasive Sacroiliac Joint Fusion Using a Novel Hydroxyapatite-Coated Screw: Preliminary 1-Year Clinical and Radiographic Results of a 2-Year Prospective Study. World Neurosurg. 2017 May;101:493-497.

13. Lee DJ, Kim SB, Rosenthal P, Panchal RR, Kim KD. Stereotactic Guidance for Navigated Percutaneous Sacroiliac Joint Fusion. J Biomed Res. 2016 Mar;30(2):162-167.

14. Cross WW, Delbridge A, Hales D, Fielding LC. Minimally Invasive Sacroiliac Joint Fusion: 2-Year Radiographic and Clinical Outcomes with a Principles-Based SIJ Fusion System Open Orthop J. 2018 Jan 17:12:7-16.

15. Duhon BS, Bitan F, Lockstadt H, Kovalsky D, Cher D, Hillen T, SIFI Study Group. Triangular Titanium Implants for Minimally Invasive Sacroiliac Joint Fusion: 2-Year Follow-Up from a Prospective Multicenter Trial. Int J Spine Surg. 2016 Apr 20;10:13

16. Darr E, Cher D. Four-Year Outcomes After Minimally Invasive Transiliac Sacroiliac Joint Fusion with Triangular Titanium Implants. Med Devices (Auckl). 2018 Aug 29;11:287-289.

17. Rudolf L, Capobianco R. Five-Year Clinical and Radiographic Outcomes After Minimally Invasive Sacroiliac Joint Fusion Using Triangular Implants. Open Orthop J. 2014 Oct 17:8:375-83.

18. Schoell K, Buser Z, Jakoi A, Pham M, Patel NN, Hsieh PC, Liu JC, Wang JC. Postoperative Complications in Patients Undergoing Minimally Invasive Sacroiliac Fusion. Spine J. 2016 Nov;16(11):1324-1332

19. Abbasi H, Hipp JA. The Assessment of Fusion Following Sacroiliac Joint Fusion Surgery. Cureus. 2017 Oct 20;9(10):e1787. 
20. Polly DW, Cher DJ, Wine KD, Whang PG, Frank CJ, Harvey CF, Lockstadt H, Glaser JA, Limoni RP, Sembrano JN; INSITE Study Group. Randomized Controlled Trial of Minimally Invasive Sacroiliac Joint Fusion Using Trianular Titanium Implants vs Nonsurgical Management for Sacroiliac Joint Dysfunction: 12-Month Outcomes. Neurosurgery. 2015 Nov;77(5):674-90.
21. Polly DW, Swofford J, Whang PG, Frank CJ, Glaser JA, Limoni RP, Cher DJ, Wine KD, Sembrano JN, INSITE Study Group. Two-Year Outcomes from a Randomized Controlled Trial of Minimally Invasive Sacroiliac Joint Fusion vs. Non-Surgical Management for Sacroiliac Joint Dysfunction. Int J Spine Surg. 2016 Aug 23;10:28.
22. Sturesson B, Kools D, Pflugmacher R Gasbarrini A, Prestamburgo D, Dengler J. Six-Month Outcomes From A Randomized Controlled Trial of Minimally Invasive SI Joint Fusion With Triangular Titanium Implants vs Conservative Management. Eur Spine J. 2017 Mar;26(3):708-719. 